\title{
Third-generation electrochemical biosensor based on nitric oxide reductase immobilized in a multiwalled carbon nanotubes/1-n-butyl-3- methylimidazolium tetrafluoroborate nanocomposite for nitric oxide detection
}

Filipa O. Gomes

Luísa B. Maia

Cristina Delerue-Matos

Isabel Moura

José J.G. Moura

Simone Morais

\section{Abstract}

Nitric oxide (NO) has a crucial role in signaling and cellular physiology in humans. Herein, a novel third-generation biosensor based on the Marinobacter hydrocarbonoclasticus metalloenzyme (nitric oxide reductase (NOR)), responsible for the NO reduction in the denitrifying processes, was developed through the direct adsorption of a new nanocomposite (multiwalled carbon nanotubes (MWCNTs)/1- $n$ butyl-3-methylimidazolium tetrafluoroborate $\left.\left(\mathrm{BMIMBF}_{4}\right) / \mathrm{NOR}\right)$ onto a pyrolytic graphite electrode (PGE) surface. The NOR direct electron transfer behavior (formal potential of $-0.255 \pm 0.003 \mathrm{~V} v s$. $\mathrm{Ag} / \mathrm{AgCl}$ ) and electrocatalysis towards $\mathrm{NO}$ reduction $(-0.68 \pm 0.03 \mathrm{~V} v s . \mathrm{Ag} / \mathrm{AgCl})$ of the PGE/[MWCNTs/BMIMBF$/ \mathrm{NOR}$ ] biosensor were investigated in phosphate buffer at $\mathrm{pH}$ 6.0. Large enzyme loading $\left(2.04 \times 10^{-10} \mathrm{~mol} / \mathrm{cm}^{2}\right)$, acceptable electron transfer rate between NOR and the PGE surface $\left(\mathrm{k}_{\mathrm{s}}=0.35 \mathrm{~s}^{-1}\right)$, and high affinity for $\mathrm{NO}\left(K_{\mathrm{m}}=2.17 \mu \mathrm{mol} \mathrm{L}^{-1}\right)$ were observed with this biosensor composition. A linear response to NO concentration $\left(0.23-4.76 \mu \mathrm{mol} \mathrm{L}^{-1}\right)$ was perceived with high sensitivity $\left(0.429 \mu \mathrm{A} / \mu \mathrm{molL}^{-1}\right)$, a detection limit of $0.07 \mu \mathrm{mol} \mathrm{L}{ }^{-1}$, appropriate repeatability $(9.1 \%$ relative standard deviations (RSD)), reproducibility (6.0-11\% RSD) and $80-102 \%$ recoveries. The biosensor was stable during 1 month retaining $79-116 \%$ of its initial response. These data confirmed that NOR incorporated in the MWCNTs/BMIMBF 4 nanocomposite can efficiently maintain its bioactivity paving a new and effective way for NO biosensing.

\section{Keywords}

Direct electron transfer

Enzymatic biosensor

Nitric oxide reductase

Nitric oxide

Multiwalled carbon nanotubes

Room temperature ionic liquid 


\section{Introduction}

Nitric oxide radical ( $\mathrm{NO}$, herein abbreviated as $\mathrm{NO}$ ), produced in humans from $\underline{\mathrm{L}}$ arginine by the action of $\mathrm{NO}$ synthases, is one of three fundamental gasotransmitters (together with hydrogen sulfide and carbon monoxide) [1, 2]. NO sensing is needed in a variety of applications, including medical and pharmaceutical industry [3] , asthma monitoring [4], human breath []ㅡ, rat kidney monitoring []ㅡ, among others. Excessive amounts of NO can damage cells and cause many pathological conditions including neurodegenerative diseases, endothelial dysfunction and cancer [7]. Therefore, the development of efficient, fast and selective methods capable of NO detection in the cellular milieu has been in the last years a hot research topic []].

In bacteria, NO is an intermediate in denitrification, a "respiratory" pathway, where $\underline{\text { nitrate is reduced to dinitrogen [9]. In this pathway, NO is reduced into nitrous oxide }}$ $\left(\mathrm{N}_{2} \mathrm{O}\right)$, in a reaction catalyzed by the specific nitric oxide reductase (NOR) enzyme $[\underline{10}, 11]$. The specificity and efficiency of this enzyme towards NO make them a very interesting target to develop a new biosensor for the NO detection. Until now, NOR has not been used in electrochemical biosensors but, concerning its electrochemical characteristics reported by few authors [[12], [13], [14], [15]], its application in thirdgeneration biosensors development could be considered. Third generation biosensors are based on the direct electron transfer (DET) of proteins, where the absence of mediator is the main advantage providing high selectivity [16]. Because they operate in a closer potential window to the redox potential of the protein, these biosensors are less prone to interfering reactions [16]. However, the stabilization of the enzyme within the biosensor can be a major problem $[\underline{17}, \underline{18}]$. Multiwalled carbon nanotubes (MWCNTs) have been widely used as solid platforms to immobilize enzymes in electrochemical biosensors due to their unique physical and chemical properties, namely easy functionalization, high electric conductivity and large surface area, enhancing the electrocatalysis [[19], [20], [21], [22]]. Additionally, room temperature ionic liquids (ILs) may act as electrolytes and solvents in biosensor design [23] being good dispersants for MWCTNs [24]. ILs are a broad class of salts that are liquid below $100^{\circ} \mathrm{C}$ [25] and have been recognized as green solvents (as alternative to volatile organic solvents) due to their negligible vapor pressure, good thermal stability and biocompatibility [26]. These sustainable characteristics offer benefits, namely simplicity of containment, recovery and recycling facility [27]. In electrochemistry, ILs also exhibit a wide potential window and appropriate intrinsic

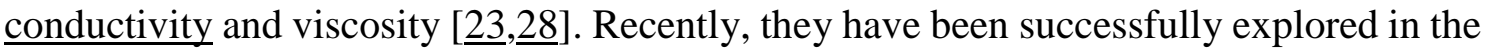
preparation of IL-carbon nanomaterial hybrids since synergistic effects have been noticed, offering unique advantages for electrodeposition, electrosynthesis and electrocatalysis [29]. Furthermore, these composite materials can also be used as

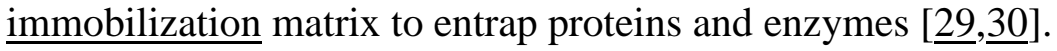

BMIMBF $_{4}$ is composed by a small anion tetrafluoroborate and a large organic cation 1$n$-butyl-3-methylimidazolium. The high potential applicability of this IL for electrochemical biosensors development can be assessed by the reported studies regarding enzymatic and heme-protein third generation biosensors (Table $1 \mathrm{~S}$ and $2 \mathrm{~S}$, Supplementary Material). The main applied enzymes (presented by decreasing order of number of studies) were glucose oxidase, horseradish peroxidase, but others, such as choline oxidase, laccase, catalase, superoxide dismutase and chloroperoxidase have been also tested but in a more limited way; the involved substrates were methomyl, superoxide anion, glucose, cholesterol, choline, trichloroacetic acid and hydrogen peroxide (Table 
1S, Supplementary Material). Furthermore, and because NOR is a hemic enzyme, the heme-protein biosensors that have been described using $\mathrm{BMIMBF}_{4}$ were also reviewed (Table 2S, Supplementary Material). Hemoglobin, myoglobin and cytochrome $c$ were exploited for $\mathrm{H}_{2} \mathrm{O}_{2}$, trichloroacetic acid and nitrite biosensing [[31], [32], [33]]. As far as we know, $\mathrm{BMIMBF}_{4}$ or NOR enzyme were not yet explored for the development of biosensors for NO.

Thus, the main aim of this study was to develop a novel third-generation enzymatic biosensor for NO determination taking advantage of the inherent features of Marinobacter hydrocarbonoclasticus NOR, MWCNTs and BMIMBF 4 . With this goal in mind, the selected metalloenzyme (which is not commercially available) was purified, characterized, and subsequently incorporated in an optimized $\mathrm{MWCNTs} / \mathrm{BMIMBF}_{4}$ nanocomposite, which was used to modify a pyrolytic graphite electrode (PGE). The DET behavior and electrocatalysis towards NO reduction of the $\mathrm{PGE} /\left[\mathrm{MWCNTs} / \mathrm{BMIMBF}_{4} / \mathrm{NOR}\right]$ biosensor were investigated. The optimized approach provided high biosensor sensitivity and stability.

\section{Materials and methods}

\subsection{Reagents}

MWCNTs-COOH (thin, extent of labeling: $>8 \%$ carboxylic acid functionalized, avg. diam. $\times$ L $9.5 \mathrm{~nm} \times 1.5 \mu \mathrm{m}), \mathrm{BMIMBF}_{4}(\geq 97.0 \%)$, 2-phenylethanol $(\mathrm{PE} ; \geq 99.0 \%)$, potassium hexa-cyanoferrate (II) trihydrate $\left(\mathrm{C}_{6} \mathrm{FeK}_{4} \mathrm{~N}_{6} .3 \mathrm{H}_{2} \mathrm{O} ; \geq 99 \%\right)$, N, Ndimethylformamide (DMF; 99\%), potassium hexa-cyanoferrate (III) $\left(\mathrm{C}_{6} \mathrm{FeK}_{3} \mathrm{~N}_{6} ; \geq 99 \%\right.$ ) were purchased from Sigma-Aldrich (Steinhein, Germany). Ethanol (EtOH; 99.5\%), sulfuric acid $\left(\mathrm{H}_{2} \mathrm{SO}_{4} ; 96 \%\right)$ and $\mathrm{n}$-dodecyl- $\beta$-D-maltoside (DM) were obtained from Panreac (Barcelona, Spain). Potassium dihydrogen phosphate $\left(\mathrm{KH}_{2} \mathrm{PO}_{4}\right.$, p.a.) and dipotassium hydrogen phosphate $\left(\mathrm{K}_{2} \mathrm{HPO}_{4}\right.$, p.a.) were used to prepare phosphate buffer (100 $\mathrm{mmolL}^{-1}, \mathrm{pH}$ 6.0); they were bought from Riedel-de-Haën (Germany) as well as potassium hydroxide (p.a.). NO solutions of different concentrations were prepared by dilution from a buffer standard stock solution of $100 \mu \mathrm{mol} \mathrm{L}^{-1}$, prepared by bubbling a $5 \% \mathrm{NO} / 95 \%$ He gas mixture (Air Liquid, Portugal) into buffer $100 \mathrm{mmolL}^{-1}$ phosphate buffer $\mathrm{pH} 6.0$ [34]. All solutions and stock were prepared immediately before being used. Ultrapure water obtained from a Millipore water purification system (18 M $\Omega$, Milli-Q, Millipore, Molsheim, France) was used in all assays.

\subsection{NOR purification and characterization}

NOR was purified from membrane extracts of Marinobacter hydrocarbonoclasticus grown anaerobically as described by Prudêncio et al. [35]; the NOR preparation used in these studies was evaluated by sodium dodecyl sulfate polyacrylamide gel electrophoresis (SDS-PAGE) (Bio-Rad, Mini-PROTEAN® Tetra Handcast Systems, Portugal) based on the protocol of Laemmli [36] and UV-vis spectrum (UV 1800-Shimadzu, 250-800 nm, Germany). An ISO-NO Mark II amperometric sensor $(2 \mathrm{~mm}$, World Precision Instruments, Inc., UK: one unit corresponds to $1 \mu \mathrm{mol}$ of $\mathrm{NO} / \mathrm{min}$ ) was used to achieve the specific activity of $760 \mathrm{U} / \mathrm{mg}(14 \mathrm{mg} / \mathrm{mL}$ ) (determined as described previously by Timóteo et al. [34]. 


\subsection{Biosensor fabrication}

Preparation of the modified electrode included the pretreatment of a pyrolytic graphite electrode (PGE; A=7.07 $\mathrm{mm}^{2}$; ALS Co., Ltd; Tokyo, Japan) and subsequent immobilization of the prepared nanocomposite on it. The PGE was successively polished with alumina powder (1.0 and $0.3 \mu \mathrm{m}$, Gravimeta Lda, Portugal), ultrasonicated with ethanol and washed with ultra-pure water for $10 \mathrm{~min}$. PGE surface activation was performed by cyclic voltammetry $(\mathrm{CV})$ in $\mathrm{H}_{2} \mathrm{SO}_{4} 0.5 \mathrm{~mol} \mathrm{~L}{ }^{-1}$ at $100 \mathrm{mV} / \mathrm{s}$ in the range of $0 \mathrm{~V}$ to $1.6 \mathrm{~V}$ vs. $\mathrm{Ag} / \mathrm{AgCl} / \mathrm{Cl}$ - sat. For the preparation of $\mathrm{MWCNTs} / \mathrm{BMIMBF}_{4} / \mathrm{NOR}$ nanocomposite, the optimum amount of $6 \mu \mathrm{L}$ of $1.0 \mathrm{mg} / \mathrm{mL}$ MWCNTs (dispersed in DMF) was mixed with $4 \mu \mathrm{L}$ of $\mathrm{BMIMBF}_{4}$ and $4 \mu \mathrm{L}$ of NOR $(760 \mathrm{U} / \mathrm{mg} ; 14 \mathrm{mg} / \mathrm{mL})$. The as prepared nanocomposite was immobilized on the PGE surface by the solvent casting technique and the solvent was evaporated with a very gentle nitrogen flow.

\subsection{Electrochemical measurements}

A three-electrode cell consisting in the modified PGE (PGE/MWCNTs; $\mathrm{PGE} /\left[\mathrm{MWCNTs} / \mathrm{BMIMBF}_{4}\right], \mathrm{PGE} /\left[\mathrm{MWCNTs} / \mathrm{BMIMBF}_{4} / \mathrm{NOR}\right]$ or PGE/NOR) as the working electrode, and a platinum wire and silver/silver chloride saturated with $\mathrm{KCl}$ $3 \mathrm{~mol} \mathrm{~L}^{-1}$ as the secondary and reference electrodes, respectively. Electrochemical experiments were performed with an Autolab PGSTAT 204 potentiostat-galvanostat controlled by GPES 4.9.7 and Nova 1.10 software (Metrohm Autolab). The assays were conducted in one conventional compartment cell using as electrolyte $100 \mathrm{mmolL}^{-1}$ of phosphate buffer with $0.02 \% \mathrm{DM}$ and $0.01 \% \mathrm{PE}$ at $\mathrm{pH} 6.0$ for NOR redox behavior and NO bioelectrocatalysis or the same buffer with $5.0 \mathrm{mmolL}^{-1}\left[\mathrm{Fe}(\mathrm{CN})_{6}\right]^{3-/ 4-}$ for characterization of the biosensor construction. The redox behavior of NOR was evaluated by $\mathrm{CV}$ applying a step potential of $3 \mathrm{mV}$ and a potential range of 0.4 to $-1.0 \mathrm{~V}$, with a previous deoxygenation of the electrolyte using high purity nitrogen gas $(99.999 \%)$ during $20 \mathrm{~min}$. NO bioelectrocatalysis was performed in the same potential window and with the same deoxygenation step using square wave voltammetry (SWV) (because of its fast electroanalytical response and high sensitivity) at a frequency of $10 \mathrm{~Hz}$, amplitude of $20 \mathrm{mV}$ and step potential of $3 \mathrm{mV}$. For each NO tested concentration, a new solution was prepared by adding an aliquot of the freshly prepared $100 \mu \mathrm{mol} \mathrm{L}-1$ NO stock standard solution [34] to the deoxygenated electrolyte solution with the help of a microsyringe. NO has a very short half-life in biological milieu (typically within the seconds range [37]), therefore, in this work, electroanalytical data were based on the maximum peak current, which was attained in the first scan.

Electrochemical impedance spectroscopy (EIS) assays were performed in the buffer solution with $5.0 \mathrm{mmolL}^{-1}\left[\mathrm{Fe}(\mathrm{CN})_{6}\right]^{3-/ 4-}\left(\mathrm{pH}\right.$ 6.0) applying a frequency range from $10^{-1}$ to $10^{5} \mathrm{~Hz}$ with an amplitude perturbation of $5 \mathrm{mV}$ and $0.2 \mathrm{~V}$ as conditioning potential.

\subsection{Morphological characterization}

The morphological biosensor characterization was realized by a High resolution Environmental Scanning Electron Microscope with X-Ray Microanalysis and Electron Backscattered Diffraction analysis: Quanta 400 FEG ESEM / EDAX Genesis X4M (Schottky).

\subsection{Statistical analysis}


Statistical analysis was performed using SPSS software (IBM SPSS Statistics 20). The non-parametric Wilcoxon Mann-Whitney $U$ test was used due to non-normal distribution of the data. Statistical significance was defined at $p \leq 0.05$.

\section{Results and discussion}

\subsection{Biosensor construction}

\subsubsection{Electrochemical characterization}

$\mathrm{CV}$ and EIS were used to characterize the impact of each modification on the electrochemical behavior and interface properties of the biosensor and thus to optimize its construction. Assays were performed with $5.0 \mathrm{mmolL}^{-1}\left[\mathrm{Fe}(\mathrm{CN})_{6}\right]^{3-/ 4-}$ as redox probe in phosphate buffer ( $\mathrm{pH} 6.0)$.

Firstly, the optimum MWCNTs:BMIMBF 4 ratio in the nanocomposite was established by testing six different proportions $(0: 10,2: 8,4: 6,6: 4,8: 2$ and 10:0 (v/v)) and maintaining constant the total drop cast volume $(10 \mu \mathrm{L})$ (Fig. 1(A)). Synergetic effects were attained since higher sensitivity was reached when both composite constituents were present, when compared with the electrode modification with only one of the individual component (MWCNTs or BMIMBF 4$)$ (Fig. 1(A) and (B)). The decrease of the MWCNTs volume from 10 till $6 \mu \mathrm{L}$ and simultaneous increase of $\mathrm{BMIMBF}_{4}$ in the nanocomposite from 0 till $4 \mu \mathrm{L}$ originated the best significant $(p<0.05)$ enhancement of the signal (72.5\% higher current for PGE/[MWCNTs/BMIMBF 4$]$ than PGE) ((Fig. 1(B)), thus the 6:4 (v/v) MWCNTs:BMIMBF 4 ratio was considered the optimum one. Moreover, it can be observed that MWCNTs contributed more significantly than $\mathrm{BMIMBF}_{4}$ to the marked positive impact on the PGE current intensity and on the process reversibility. These data are in accordance with the MWCNTs properties, i.e. high electric

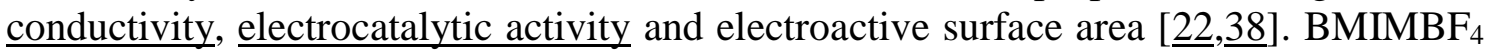
has high viscosity $\left(99.9 \mathrm{cP}\right.$ at $20^{\circ} \mathrm{C}$ [39]; which may increase the resistance), but may support charge transport by behaving as a fortifying source of ion carriers (conductivity of $0.35 \mathrm{~S} / \mathrm{m}$ at $25^{\circ} \mathrm{C}[\underline{39}, \underline{40]}$. This electrochemical behavior is in agreement with those observed by Zhang et al. [41] and Shangguan et al. [42]. 


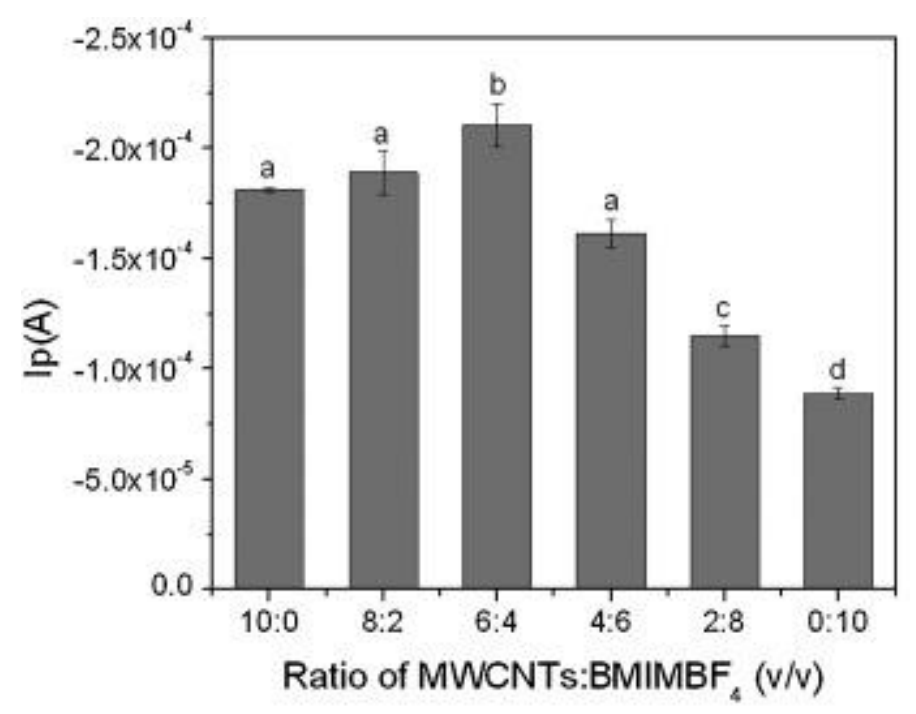

(A)

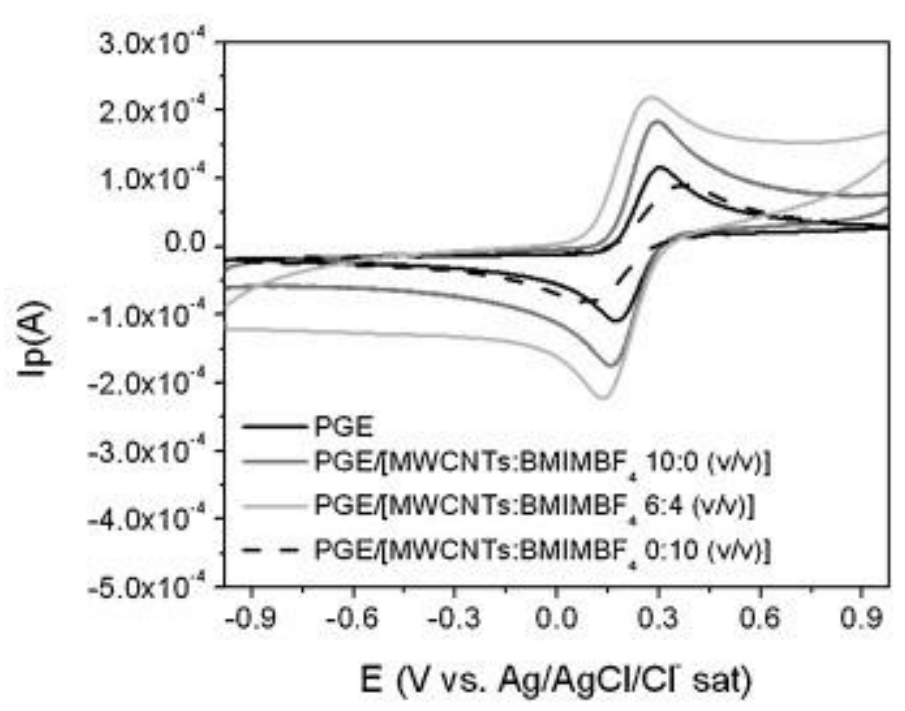

(B)

Fig. 1. Optimization of the MWCNTs:BMIMBF 4 ratio: (A) Effect of the MWCNTs:BMIMBF 4 ratio (10:0, 8:2, 6:4, 4:6, 2:8 and 0:10, $\mathrm{v} / \mathrm{v}$ ) on the peak current of the modified pyrolytic graphite electrode (PGE). Different letters indicate that the given medians are significantly different (Wilcoxon Mann-Whitney at $p<0.05$ ). (B) Cyclic voltammograms of the bare and modified PGE with the MWCNTs:BMIMBF 4 ratio (v/v) of 10:0 (PGE/MWCNTs), 6:4 (PGE/[MWCNTs/BMIMBF 4 ]) and 0:10 (v/v) $\left(\mathrm{PGE} / \mathrm{BMIMBF}_{4}\right)$. Experimental conditions: $5.0 \mathrm{mmolL}^{-1}\left[\mathrm{Fe}(\mathrm{CN})_{6}\right]^{3-4-4}$ in phosphate buffer $(\mathrm{pH} 6.0)$ at $100 \mathrm{mV} / \mathrm{s}$.

Fig. 2 displays the representative cyclic voltammograms (Fig. 2(A)) and the impedance spectra represented as Nyquist plots (Fig. 2(B)) of the PGE, PGE/NOR, PGE/[MWCNTs/BMIMBF 4 , $\quad$ PGE/[MWCNTs/NOR] and $\mathrm{PGE} /\left[\mathrm{MWCNT} / \mathrm{BMIMBF}_{4} / \mathrm{NOR}\right]$. The impedance spectra were fitted to the Randles equivalent electric circuit with a constant phase element with charge transfer resistance indicated by the diameter of the semicircle [43], while the linear part locating at lower frequency gave information on the diffusion process [42]. The observed changes in the cyclic voltammograms (Fig. 2(A)), caused by enzyme incorporation, are in general agreement with those exhibited by the EIS profiles (Fig. 2(B)) of the different modified electrodes suggesting the successful immobilization of MWCNTs/BMIMBF $4 / \mathrm{NOR}$ or simply NOR at the PGE surface. The charge transfer resistance (Rct) increased from 81.7 to $147 \Omega$ (1.8 times higher) and to $255 \Omega$ (three fold change) after NOR adsorption onto 
the PGE surface and PGE/MWCNTs, respectively, while a tenfold increment was noticed between the Rct values of PGE/[MWCNTs/BMIMBF 4 (33.8 $\Omega)$ and PGE/[MWCNTs/BMIMBF $4 / \mathrm{NOR}]$ (360 $\Omega$ ). In agreement with previous studies, the inclusion of the enzyme on the proposed nanocomposite promoted a significant increase of the semi-circle in the impedimetric plots [44]. A similar Rct of $300 \Omega$ was reported by Karimi et al. [45] for another biosensor based on cholesterol oxidase incorporated in $\mathrm{NH}_{2}-$ MWCNTs/BMIMBF 4 nanocomposite and adsorbed onto a glassy carbon electrode [45]. NOR at pH 6.0 is positively charged [46] and hence can bind to $\mathrm{BMIMBF}_{4}$ and the MWCNTs through ionic interactions. Additionally, $\mathrm{BMIMBF}_{4}$ may interact with the carbon nanotubes by $\pi-\pi, \pi$-cationic and/or hydrophobic-hydrophobic interactions $[47,48]$. For that reason, the selected IL combined with the MWCNTs had an essential role in NOR entrapment.

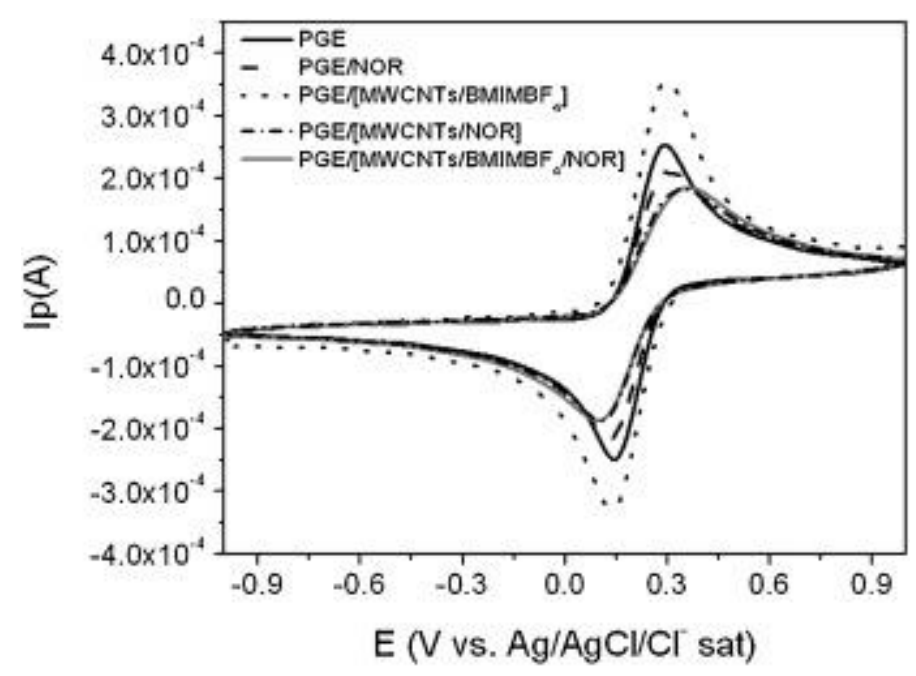

(A)

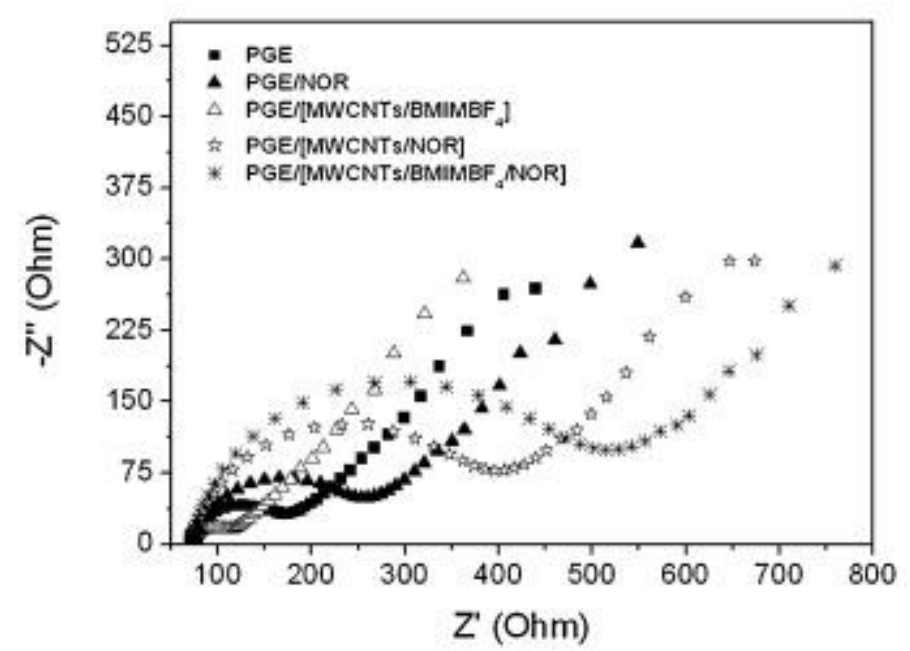

(B)

Fig. 2. Effect of enzyme immobilization on (A) cyclic voltammetric behavior and (B) Nyquist plots of the PGE, PGE/MWCNTs and PGE/[MWCNTs/BMIMBF 4 in $5.0 \mathrm{mmolL}^{-1}\left[\mathrm{Fe}(\mathrm{CN})_{6}\right]^{3-4-}$ in phosphate buffer $(\mathrm{pH}$ 6.0). Cyclic voltammetry parameters: scan rate of $100 \mathrm{mV} / \mathrm{s}$ and step potential of $3 \mathrm{mV}$. Electrochemical impedance spectroscopy conditions: frequency range from $10^{-1}$ to $10^{5} \mathrm{~Hz}$ with an amplitude perturbation of $5 \mathrm{mV}$ and $0.2 \mathrm{~V}$ as conditioning potential. 


\subsubsection{Morphological characterization}

Since the electrochemical responses are also dependent of the surface morphology, SEM characterization of each modified electrode (PGE/MWCNTs, $\mathrm{PGE} /\left[\mathrm{MWCNTs} / \mathrm{BMIMBF}_{4}\right]$ and $\left.\mathrm{PGE} /\left[\mathrm{MWCNT} / \mathrm{BMIMBF}_{4} / \mathrm{NOR}\right]\right)$ was performed to complement the electrochemical data. Representative SEM images spectra are exhibited in Fig. 3. Fig. 3 -(A) shows the typical morphology of well-dispersed functionalized MWCNTs onto the electrode surface, which displays a spaghetti-like porous reticular structure with MWCNTs entangled in one another [47]. After mixing BMIMBF 4 with MWCNTs (Fig. 3(B)), the pores of the MWCNTs network were fully eliminated and filled with the viscous IL increasing the uniformity and smoothness of the film, being in accordance with previous studies [47]. This layer (MWCNTs/BMIMBF 4$)$, as it can be noticed in Fig. 3(C), provided an adequate microenvironment for NOR entrapment by combining the solvation ability (and high ionic conductivity) of the selected IL with the high tensile strength (and electric conductivity) of MWCNTs [느, $\underline{45}, \underline{47}]$.

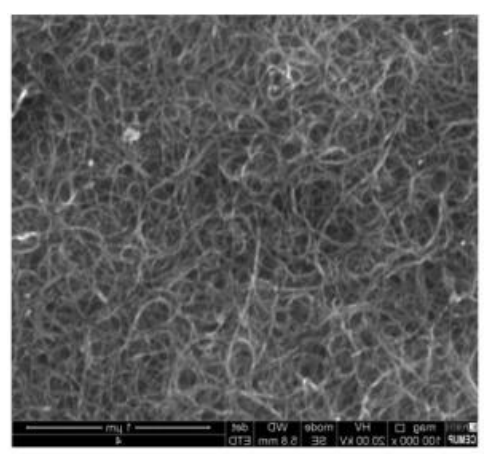

(A)

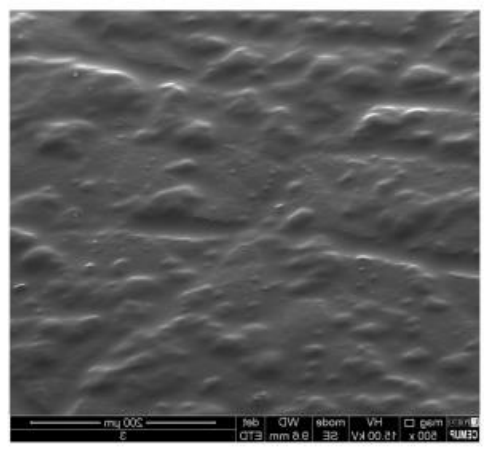

(a)

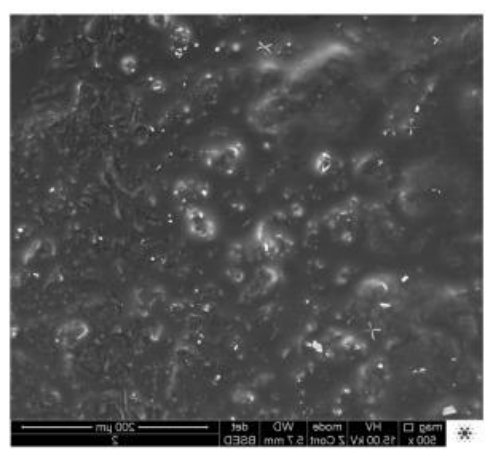

(ग)

Fig. 3. Scanning electron microscopy images of (A) PGE/MWCNTs, (B) PGE/[MWCNTs/BMIMBF 4 and (C) $\mathrm{PGE} /\left[\mathrm{MWCNTs} / \mathrm{BMIMBF}_{4} / \mathrm{NOR}\right]$. 


\subsection{Direct electron transfer behavior of NOR on the PGE/[MWCNTs/BMIMBF 4 /NOR] biosensor}

The DET behavior of NOR on the proposed biosensor immersed in $100 \mathrm{mmolL}^{-1}$ phosphate buffer, $0.02 \% \mathrm{DM}$ and $0.01 \% \mathrm{PE}$ at $\mathrm{pH} 6.0$ is presented in Fig. 4. Since enzymatic activity is markedly influenced by the $\mathrm{pH}$, all assays were executed at the optimum $\mathrm{pH}$ for NOR, i.e. 6.0 [14]. The electrochemical response of NOR corresponded to a pair of well-defined cathodic and anodic peaks (Fig. 4 at $-0.261 \pm 0.003$ and $-0.249 \pm 0.002 \mathrm{~V}$ (formal potential of $-0.255 \pm 0.003 \mathrm{~V}$ ), respectively, at scan rate of $0.25 \mathrm{~V} / \mathrm{s}$, which is ascribed to the heme $b_{3}$ center in the bi-nuclear site of NOR [14]. Good linearity was obtained between the peak current and the scan rate $(0.150-0.750 \mathrm{~V} / \mathrm{s})$ for both anodic and cathodic signals (Fig. 4) $\left(\mathrm{I}_{\mathrm{pa}}(\mathrm{A})=1.44 \times 10^{-5} \pm 6.14 \times 10^{-7} \mathrm{v}(\mathrm{V} / \mathrm{s})\right.$ $1.73 \times 10^{-6} \pm 2.58 \times 10^{-7} ; \mathrm{r}^{2}=0.991 ; \mathrm{n}=6$ and $\mathrm{I}_{\mathrm{pc}}(\mathrm{A})=-1.82 \times 10^{-5} \pm 4.53 \times 10^{-7} \mathrm{v}$ $\left.(\mathrm{V} / \mathrm{s})+1.92 \times 10^{-6} \pm 1.90 \times 10^{-7} ; \mathrm{r}^{2}=0.997 ; \mathrm{n}=6\right)$ indicative of a characteristic surfacecontrolled electrochemical process as anticipated for immobilized structures [49]. Moreover, the formal potential was not dependent of the scan rate pointing to a facile charge transfer kinetic in the tested range of scan rates $(150-750 \mathrm{mV} / \mathrm{s})$ [47].

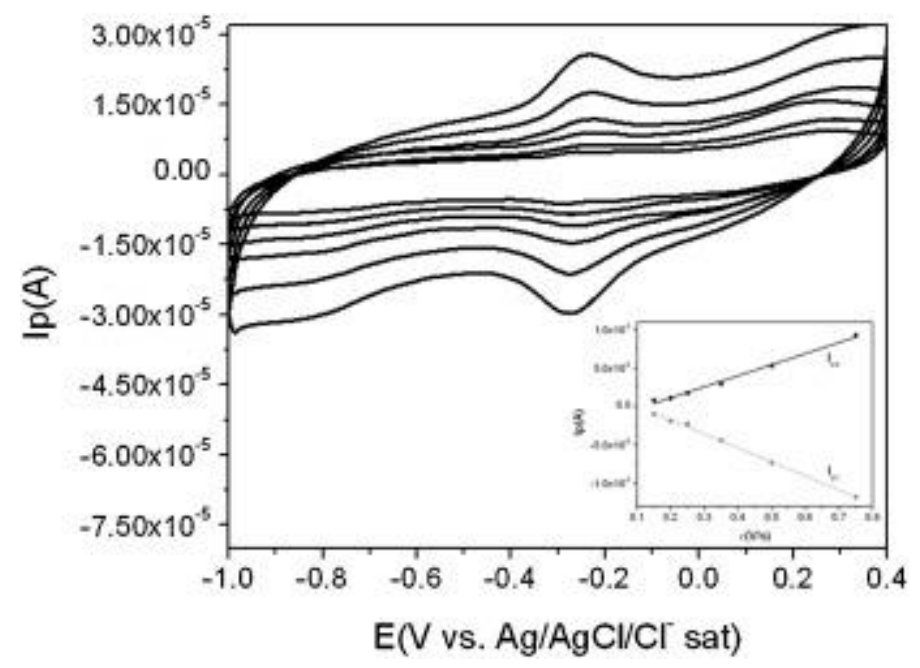

Fig. 4. Cyclic voltammograms of direct electrochemical behavior of NOR on PGE/[MWCNTs/BMIMBF $/ \mathrm{NOR}$ biosensor in 100 $\mathrm{mmolL}^{-1}$ of phosphate buffer with $0.02 \% \mathrm{n}$-dodecyl- $\beta$-D-maltoside and $0.01 \%$ 2-phenylethanol (pH 6.0) at several scan rates (150, $200,250,350,500$ and $750 \mathrm{mV} / \mathrm{s})$. Inset: Anodic $\left(\mathrm{I}_{\mathrm{pa}}\right)$ and cathodic $\left(\mathrm{I}_{\mathrm{pc}}\right)$ peak current $v s$ the scan rate.

The NOR surface coverage $\left(\tau^{*}, \mathrm{~mol} / \mathrm{cm}^{2}\right)$ of the biosensor was estimated based on Eq. (1):(1) $\mathrm{Q}=\mathrm{nFA} \tau^{*}$ where $\mathrm{Q}$ (A.s) is the charge involved in the reaction, $\mathrm{A}\left(\mathrm{cm}^{2}\right)$ is the geometric area of the working electrode, $\mathrm{n}$ is the number of the electron transferred, and $\mathrm{F}(\mathrm{s} . \mathrm{A} / \mathrm{mol})$ is the Faraday constant [50]. The obtained $\tau^{*}$ value $\left(2.04 \times 10^{-10} \mathrm{~mol} / \mathrm{cm}^{2}\right)$ indicated a high quantity of adsorbed NOR due to the large specific surface area of the nanocomposite-modified PGE. This is the first time that NOR was used to prepare a biosensor, but some previous catalytic studies, with NOR directly adsorbed onto the PGE, reported a one order of magnitude lower value of surface coverage $\left(1.52 \times 10^{-11}\right.$ $\left.2.37 \times 10^{-11} \mathrm{~mol} / \mathrm{cm}^{2}\right)$ [[12], [13], [14]] evidencing the advantages of the proposed immobilization approach. Moreover, the previously reported $\tau^{*}$ for enzymatic and hemebased-biosensors that included $\mathrm{BMIMBF}_{4}$ ranged from $4.18 \times 10^{-12}$ to $9.07 \times 10^{-9}$ $\mathrm{mol} / \mathrm{cm}^{2}$ and $1.39 \times 10^{-11}$ to $6.81 \times 10^{-8} \mathrm{~mol} / \mathrm{cm}^{2}$, respectively (Tables $1 \mathrm{~S}-2 \mathrm{~S}$, Supplementary Material). Both lowest values of surface coverage were obtained for biosensors that did not include nanomaterials in their construction $[\underline{51}, \underline{52}]$. On the other 
hand, the higher loadings were reported when enzyme immobilization involved carbon nanomaterials [31,53]. Recently, Kang et al. [31] reported very high $\tau^{*}\left(6.81 \times 10^{-8}\right.$ to $\mathrm{mol} / \mathrm{cm}^{2}$ ) for a carbon ionic liquid electrode modified with a biocomposite composed by myoglobin, $\mathrm{BMIMBF}_{4}$, graphene and cobalt oxide nanoflower, possibly due to the porous and three-dimensional structure of the nanoflowers combined with the use of other nanomaterials. Comparable values as the one reached in this study were reported for biosensors based on catalase [47], horseradish peroxidase [54] and hemoglobin [55] developed for hydrogen peroxide detection.

According to Laviron theory [56], and since the potential separation of the peaks was less than $200 \mathrm{mV}$, the electron transfer rate constant $\left(\mathrm{k}_{\mathrm{s}}, \mathrm{s}^{-1}\right)$ was calculated using Eq. (2): $(2) \mathrm{k}_{\mathrm{s}}=\mathrm{mnFv} / \mathrm{RT}$ where $\mathrm{m}$ is the parameter related to peak potential separation $(\mathrm{V}), \mathrm{n}$ the number of electrons involved in the reaction, $v$ is the scan rate $(\mathrm{V} / \mathrm{s})$ and all other symbols have their usual meanings. A $\mathrm{k}_{\mathrm{s}}$ value of $0.35 \mathrm{~s}^{-1}$ was obtained being in the same range as those described for some enzymatic biosensors $\left(0.51 \mathrm{~s}^{-1}\right.$ for glucose oxidase [42]; 0.55 [ [ 57] and $0.655 \mathrm{~s}^{-1}$ [58] for horseradish peroxidase; $0.7 \mathrm{~s}^{-1}$ for chloroperoxidase [59]; and $0.78 \mathrm{~s}^{-1}$ for choline oxidase based-biosensor [53]) and heme-based biosensors $\left(0.406 \mathrm{~s}^{-1}\right.$ [60], $0.5525 \mathrm{~s}^{-1}$ [61], 0.63-0.70 s $\mathrm{s}^{-1}$ [55] and $0.725 \mathrm{~s}^{-1}$ [62] for hemoglobin based-biosensors; $0.610 \mathrm{~s}^{-1}[\underline{63}]$ and $0.675 \mathrm{~s}^{-1}[\underline{31}]$ for myoglobin based devices) with $\mathrm{BMIMBF}_{4}$ (Table 1S-2S, Supplementary Material). This information demonstrated that the electron transfer between NOR and the modified electrode is efficiently mediated by the developed nanocomposite.

\subsection{Nitric oxide reduction on the $\mathrm{PGE} /[\mathrm{MWCNT} / \mathrm{BMIMBF} / \mathrm{NOR}]$ biosensor}

To investigate the electrocatalytic activity of NOR towards NO reduction, SWV voltammograms (at the optimal conditions of $10 \mathrm{~Hz}$ frequency, $20 \mathrm{mV}$ amplitude and $3 \mathrm{mV}$ step potential) were executed in $100 \mathrm{mmolL}^{-1}$ phosphate buffer, $0.02 \% \mathrm{DM}$ and $0.01 \%$ PE (pH 6.0). The obtained results are illustrated in Fig. 5. NOR entrapped on MWCNTs/BMIMBF 4 acts as an effective catalyst towards reduction of NO, with an irreversible peak at $-0.68 \pm 0.03 \mathrm{~V}$ (Fig. 5). Moreover, the biosensor response to $0.50-$ $6.98 \mu \mathrm{mol} \mathrm{L}^{-1}$ of NO was evaluated. Linearity with low dispersion of data $\left(\mathrm{I}_{\mathrm{pc}}(\mathrm{A})=-\right.$ $\left.4.29 \times 10^{-7} \pm 2.48 \times 10^{-8}[\mathrm{NO}]\left(\mu \mathrm{molL}^{-1}\right)-1.24 \times 10^{-7} \pm 6.84 \times 10^{-8} ; \mathrm{n}=6\right)$ and appropriate correlation coefficient $(0.991)$ was perceived till $4.76 \mu \mathrm{mol} \mathrm{L}^{-1}$, which was followed by saturation of the signal tending to a plateau after $5.88 \mu \mathrm{mol} \mathrm{L}^{-1}$ (characteristic of enzymatic kinetics of second order [63]) (ig. 5). The limit of detection (LOD) and limit of quantification (LOQ) were assessed as being 0.07 and $0.23 \mu \mathrm{molL}^{-1}$, respectively, based on $3^{*}$ Sy-intercept/slope (for LOD) and 10*Sy-intercept/slope (for LOQ), where Sy-intercept is the standard deviation of the y-intercept [65]. Satisfactory sensitivity of $0.429 \mu \mathrm{A} / \mu \mathrm{molL}^{-1}$ was also established. These data compare favorably with those described by $\mathrm{Xu}$ et al. [66] for hemoglobin and myoglobin-based biosensors using $\mathrm{HIMIMPF}_{6}$ and didodecyldimethylammonium bromide (linear ranges from 1.8 to 21.6 and 1.8-23 $\mu \mathrm{molL}^{-1}$ with no reported LOD and LOQ) and by Zhang et al. [41] for a basal plane graphite electrode modified by successive layers of nafion/ethanol, EMIMBF$_{4} /$ ethanol and myoglobin (linearity between $0.7-7.0 \mu \mathrm{mol} \mathrm{L}^{-1}$ and a LOD of $0.2 \mu \mathrm{mol} \mathrm{L}^{-1}$ ). Only these two studies were found concerning NO biosensors that include an IL and heme-proteins in their construction. The immunological function and the pathological effects of NO are associated with high nanomolar to low micromolar concentrations $[\underline{67}, \underline{68}]$. Thus, the attained figures of merit are appropriate to allow 
application of the developed biosensor to detect NO levels in real biological samples, namely those related with modulation of blood flow, cardiovascular pathologies,

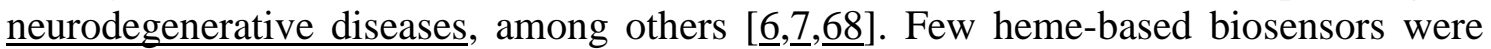
tested in rat liver, brain and raw blood describing concentrations ranging from 0.6 to $2.5 \mu \mathrm{molL}^{-1}[[69],[70],[71],[72],[73]]$. Higher concentrations, in the range of 3.91$4.92 \mu \mathrm{mol} \mathrm{L}^{-1} \mathrm{NO}$, were reported by Abdelwahab et al. [70], demonstrating that the proposed biosensor could also be used in gastric adenocarcinoma and colon adenocarcinoma diagnosis.

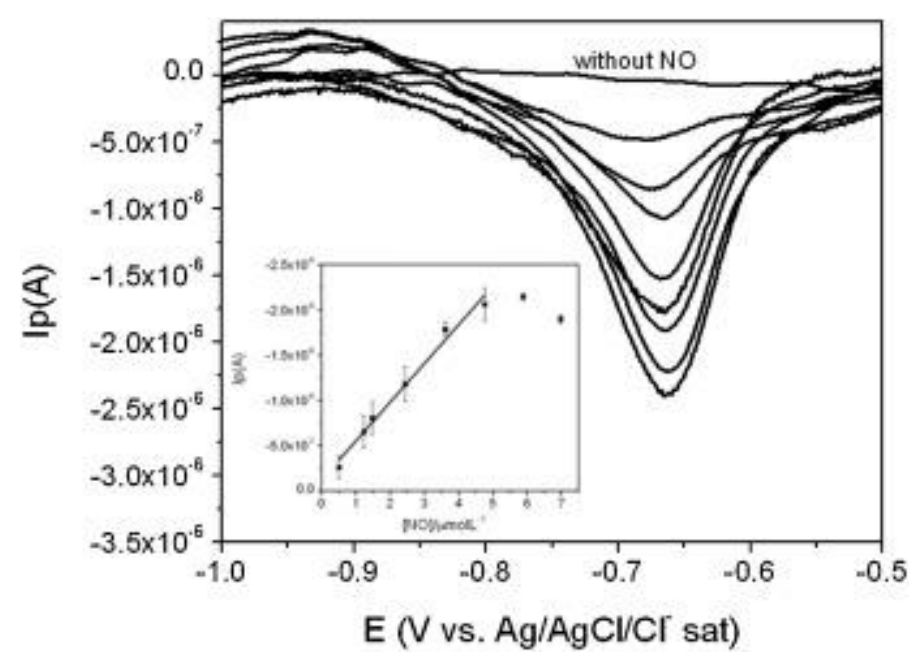

Fig. 5. Square wave voltammograms obtained with $\mathrm{PGE} /[\mathrm{MWCNT} / \mathrm{BMIMBF} / \mathrm{NOR}]$ biosensor in the absence of NO and in the presence of standard NO concentrations of $0.50,1.23,1.48,2.44,3.61$ and $4.76 \mu \mathrm{mol} \mathrm{L}^{-1}$ in $100 \mathrm{mmolL}^{-1}$ of phosphate buffer with $0.02 \%$ n-dodecyl- $\beta$-D-maltoside and $0.01 \%$ 2-phenylethanol ( $\mathrm{pH}$ 6.0). Inset: Peak current vs NO concentration and respective linearity zone. Experimental conditions: frequency of $10 \mathrm{~Hz}$, amplitude of $20 \mathrm{mV}$ and step potential of $3 \mathrm{mV}$.

The affinity of a substrate for the enzymatic centre can be assessed by the MichaelisMenten constant $\left(K_{\mathrm{m}}, \mathrm{molL}^{-1}\right)$, which decreases as the enzyme affinity increases [64]. Biochemically, it indicates a higher probability of formation of the NOR-NO intermediate, which originates an increased NO concentration to be electrochemically reduced. $K_{\mathrm{m}}$ was estimated by the Lineweaver-Burk Eq. (3):(3) $1 / \mathrm{I}_{\mathrm{p}}=K_{\mathrm{m}} / \mathrm{I}_{\max } \times 1 /[\mathrm{NO}]+1 / \mathrm{I}_{\max }$ where $\mathrm{I}_{\mathrm{p}}(\mathrm{A})$ is the current after addition of the substrate; [NO] (molL ${ }^{-1}$ ) is the concentration of the substrate and $\mathrm{I}_{\max }(\mathrm{A})$ is the maximum current measured [56]. The value obtained for the PGE/[MWCNTs/BMIMBF $4 / N O R]$ biosensor of $2.17 \mu \mathrm{mol} \mathrm{L}^{-1}$ indicated high bioactivity performance, which could be ascribed to the ionic microenvironment generated by the prepared $\mathrm{MWCNTs} / \mathrm{BMIMBF}_{4}$ nanocomposite, allowing NOR to retain its native structure and high affinity towards its natural substrate, and at the same time promoting efficient NOR-substrate interaction. To the best of our knowledge, no Michaelis Menten constant was yet established for NO biosensors that include the selected IL $\left(\mathrm{BMIMBF}_{4}\right)$ or other IL $[\underline{41}, \underline{66}]$. In general, the achieved $K_{\mathrm{m}}$ is significantly lower than those reported for heme-based (0.16$\left.17870 \mu \mathrm{mol} \mathrm{L}^{-1}\right)$ and enzymatic $\left(0.118-9800 \mu \mathrm{mol} \mathrm{L}^{-1}\right)$ biosensors using $\mathrm{BMIMBF}_{4}$ (Table 1S-2S, Supplementary Material) with some exceptions [45, 47, 51, 61, [74], [75], [76], [77], [78], [79]]. The best reported affinity was reached for laccase immobilized in

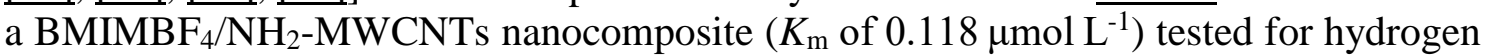
peroxide quantification [47]; for heme-protein biosensors $0.16 \mu \mathrm{mol} \mathrm{L}^{-1}$ was attained for hemoglobin incorporated in a chitosan/graphene/BMIMBF 4 matrix proposed for nitromethane biosensing [79]. 
The repeatability and reproducibility of the PGE/[MWCNTs/BMIMBF $4 / \mathrm{NOR}]$ biosensor were examined by the relative standard deviation (RSD) of several experiments. The reduction current of $2.44 \mu \mathrm{mol} \mathrm{L}{ }^{-1} \mathrm{NO}$ was measured during six independent assays and a RSD of $9.1 \%$ was displayed showing that the proposed approach had high repeatability. Concerning reproducibility, it was tested with eight biosensors, independently prepared under equivalent experimental circumstances, and the RSD varied from $6.0 \%$ (at $4.76 \mu \mathrm{mol} \mathrm{L}^{-1}$ ) to $11 \%$ (at $0.50 \mu \mathrm{mol} \mathrm{L}^{-1}$ ), indicating good reproducibility. Recovery values ranged from 80 to $102 \%$ for concentrations in the $0.50-4.76 \mu \mathrm{mol} \mathrm{L}^{-1}$ range. Further assays proved the high selectivity of NOR towards NO even in the presence of physiologically important species that may be simultaneously present with NO (or can be sponsors of NO production) in biological milieus, namely, ascorbic acid $\left(20 \mu \mathrm{mol} \mathrm{L}^{-1}\right)$, sodium nitrite $\left(200 \mu \mathrm{mol} \mathrm{L}^{-1}\right)$ and nitrate $\left(200 \mu \mathrm{mol} \mathrm{L}^{-1}\right)$, as well as glucose $\left(800 \mu \mathrm{mol} \mathrm{L}{ }^{-1}\right)$. Recovery values varied from $91.4 \pm 3.0 \%$ (sodium nitrite) to $98.4 \pm 8.9 \%$ (glucose) confirming the non-significant interference of these compounds. In addition, the long-term stability and electroanalytical performance of the developed biosensor was intermittently (once or twice per week) characterized during one month. The results showed that the developed biosensor was active and retained $79-116 \%$ of its initial response during all the tested period. Although the hydrophobic yet hygroscopic properties of the selected IL [으] , these data indicated that no significant leaching of any of the three nanocomposite components (MWCNTs, $\mathrm{BMIMBF}_{4}$ and NOR) occurred from the biosensing surface during one month. These results can be explained by the fact that $\mathrm{BMIMBF}_{4}$ is not simply and directly adsorbed at the PGE surface; it is mixed with MWCNTs and NOR (28.6\% (v/v/v) of $\mathrm{BMIMBF}_{4}$ in the nanocomposite) forming a stable nanocomposite, where interactions (ionic interactions, $\pi-\pi, \pi$-cationic and/or hydrophobic-hydrophobic interactions $[\underline{47}, \underline{48}])$ between the three components occur. Moreover, the stability results attained in this study are in clear agreement with those previously reported for enzymatic and heme-based biosensors (Tables $1 \mathrm{~S}$ and $2 \mathrm{~S}$; Supplementary Material). These data confirmed that NOR incorporated in the MWCNTs/BMIMBF 4 nanocomposite can efficiently maintain its bioactivity for a significant period of time.

\section{Conclusions}

The importance of NO in signaling and cellular physiology in humans has been increasingly recognized in biomedical sciences over the last decade, what has led to an exponential growth in the development of new methods and tools. In this work, a $\mathrm{MWCNTs}_{\mathrm{BMIMBF}}$ nanocomposite was successfully developed to entrap NOR, for the first time, and prepare a novel third-generation enzymatic biosensor for NO detection. The excellent electric conductivity, together with the large surface area of MWCNTs, combined with the suitable biocompatibility, viscosity and ionic conductivity of the selected IL provided a suitable microenvironment for the immobilization of NOR and for preservation of its activity. Synergetic effects were perceived between MWCNTs and $\mathrm{BMIMBF}_{4}$, which facilitated the direct electron transfer between NOR and the transducer and the unmediated NOR-NO interaction. Therefore, these results suggest that this novel $\mathrm{PGE} /\left[\mathrm{MWCNTs} / \mathrm{BMIMBF}_{4} / \mathrm{NOR}\right]$ biosensor can be a simple, sensitive and excellent strategy for bioelectrochemical NO biomonitoring applications. 


\section{Acknowledgments}

FG thanks FCT/MCTES for the fellowship grant SFRH/BD/52502/2014, which is financed by national funds and co-financed by FSE. LBM thanks to FCT/MCTES for the CEEC-Individual 2017 Program Contract. This work was supported by the PTDC/BBBQB/0129/2014 project (FCT/MCTES) and also by the Associate Laboratory Research Unit for Green Chemistry - Technologies and Processes Clean - LAQV, financed by national funds from FCT/MEC (UID/QUI/50006/2019) and co-financed by the ERDF under the PT2020 Partnership Agreement (POCI-01-0145-FEDER-007265). Funding through REQUIMTE project entitled "NOR-based biosensor for nitric oxide detection in biological and environmental samples" is also acknowledged. The financial support from the European Union (FEDER funds through COMPETE) and National Funds (Fundação para a Ciência e Tecnologia-FCT) through project PTDC/ASP-PES/29547/2017, by FCT/MEC with national funds and co-funded by FEDER, is also acknowledged.

\section{References}

$[1]$

N. Kumar, V. Bhalla, M. KumarRecent developments of fluorescent probes for the detection of gasotransmitters $\left(\mathrm{NO}, \mathrm{CO}\right.$ and $\mathrm{H}_{2} \mathrm{~S}$ )

Coord. Chem. Rev., 257 (2013), pp. 2335-2347, 10.1016/j.ccr.2013.02.028

[2]

$\mathrm{X}$. Zhou, S. Lee, Z. Xu, J. YoonRecent progress on the development of chemosensors for gases

Chem. Rev., 115 (2015), pp. 7944-8000, 10.1021/cr500567r

[3]

C.W. Chang, G. Maduraiveeran, J.C. Xu, G.W. Hunter, P.K. DuttaDesign, fabrication, and testing of MEMS-based miniaturized potentiometric nitric oxide sensors

Sens. Actuators B Chem., 204 (2014), pp. 183-189, 10.1016/j.snb.2014.06.108

$[4]$

H.K. Gatty, S. Leijonmarck, M. Antelius, G. Stemme, N. RoxhedAn amperometric nitric oxide sensor with fast response and ppb-level concentration detection relevant to asthma monitoring

Sens. Actuators B Chem., 209 (2015), pp. 639-644, 10.1016/j.snb.2014.11.147

C. Sun, G. Maduraiveeran, P. DuttaNitric oxide sensors using combination of p- and n-type semiconducting oxides and its application for detecting NO in human breath

Sens. Actuators B Chem., 186 (2013), pp. 117-125, 10.1016/j.snb.2013.05.090 
[6]

Y. Peng, Y. Ji, D. Zheng, S. HuIn situ monitoring of nitric oxide release from rat kidney at poly(eosin-b)-ionic liquid composite-based electrochemical sensors

Sens. Actuators B Chem., 137 (2009), pp. 656-661, 10.1016/j.snb.2009.01.003

[7]

V. Calabrese, C. Mancuso, M. Calvani, E. Rizzarelli, D.A. Butterfield, A.M. StellaNitric oxide in the central nervous system: neuroprotection versus neurotoxicity

Nat. Rev. Neurosci., 8 (2007), pp. 766-775, 10.1038/nrn2214

[8]

D. O'HareBiosensors and sensor systems

G.Z. Yang (Ed.), Body Sensor Networks., Springer, London (2014), pp. 55-115

[9]

J.A. ColeNitric oxide production, damage and management during anaerobic nitrate reduction to ammonia

I. Moura, J.J.G. Moura, S.R. Pauleta, L.B. Maia (Eds.), Metalloenzymes in Denitrification: Applications and Environmental Impacts, Royal Society of Chemistry (2016), pp. 11-38

Y. ShiroStructure and function of bacterial nitric oxide reductases: nitric oxide reductase, anaerobic enzymes

Biochim. Biophys. Acta, 1817 (2012), pp. 1907-1913, $\underline{10.1016 / \text { j.bbabio.2012.03.001 }}$

N.J. Watmough, S.J. Field, R.J.L. Hughes, D.J. RichardsonThe bacterial respiratory nitric oxide reductase

Biochem. Soc. Trans., 37 (2009), pp. 392-399, 10.1042/BST0370392

C.M. Cordas, A.G. Duarte, J.J.G. Moura, I. MouraElectrochemical behaviour of bacterial nitric oxide reductase - evidence of low redox potential non-heme $\mathrm{Fe}_{B}$ gives new perspectives on the catalytic mechanism

Biochim. Biophys. Acta, $1827 \quad$ (2013), pp. 233-238, $\underline{10.1016 / \text { j.bbabio.2012.10.018 }}$

C.M. Cordas, A.S. Pereira, C.E. Martins, C.G. Timoteo, I. Moura, J.J. Moura, P. TavaresNitric oxide reductase: direct electrochemistry and electrocatalytic activity 
Chembiochem., 7 (2006), pp. 1878-1881, 10.1002/cbic.200600253

$[14]$

A.G. Duarte, C.M. Cordas, J.J.G. Moura, I. MouraSteady-state kinetics with nitric oxide reductase (NOR): new considerations on substrate inhibition profile and catalytic mechanism

Biochim. Biophys. Acta, 1837 (2014), pp. 375-384, $\underline{10.1016 / j . b b a b i o .2014 .01 .001}$

$[15]$

S. Ramos, R.M. Almeida, C.M. Cordas, J.J.G. Moura, S.R. Pauleta, I. MouraInsights into the recognition and electron transfer steps in nitric oxide reductase from Marinobacter hydrocarbonoclasticus

J. Inorg. Biochem., 177 (2017), pp. 402-411, 10.1016/j.jinorgbio.2017.09.001

W. Zhang, G. LiThird-generation biosensors based on the direct electron transfer of proteins

Anal. Sci., 20 (2004), pp. 603-609, 10.2116/analsci.20.603

J.M. GuisanImmobilization of Enzymes as the 21st Century Begins

Humana Press (2006), pp. 1-13

N. Rueda, J.C.S. dos Santos, C. Ortiz, R. Torres, O. Barbosa, R.C. Rodrigues, A. Berenguer-Murcia, R. Fernandez-LafuenteChemical modification in the design of immobilized enzyme biocatalysts: drawbacks and opportunities Chem. Rec., 16 (2016), pp. 1436-1455, 10.1002/tcr.201600007

X. Che, R. Yuan, Y. Chai, J. Li, Z. Song, W. Li, X. ZhongA glucose biosensor based on chitosan-Prussian blue-multiwall carbon nanotubes-hollow PtCo nanochains formed by one-step electrodeposition

Colloids Surf. B Biointerfaces, 84 (2011), pp. 454-461, $\underline{10.1016 / j . c o l s u r f b .2011 .01 .041 ~}$

G. Fu, Z. DaiEfficient immobilization of glucose oxidase by in situ photocross-linking for glucose biosensing

Talanta, 97 (2012), pp. 438-444, 10.1016/j.talanta.2012.04.059

F.W.P. Ribeiro, M.F. Barroso, S. Morais, S. Viswanathan, P. de Lima-Neto, A.N. Correia, M.B.P.P. Oliveira, C. Delerue-MatosSimple laccase-based biosensor for formetanate hydrochloride quantification in fruits 
Bioelectrochemistry, 95 (2014), pp. 7-14, 10.1016/j.bioelechem.2013.09.005

T.M. Oliveira, M. Fatima Barroso, S. Morais, P. de Lima-Neto, A.N. Correia, M.B.P.P. Oliveira, C. Delerue-MatosBiosensor based on multi-walled carbon nanotubes paste electrode modified with laccase for pirimicarb pesticide quantification

Talanta, 106 (2013), pp. 137-143, 10.1016/j.talanta.2012.12.017

$[23]$

M. Galiński, A. Lewandowski, I. StępniakIonic liquids as electrolytes

Electrochim. Acta, 51 (2006), pp. 5567-5580, 10.1016/j.electacta.2006.03.016

N. Hameed, J.S. Church, N.V. Salim, T.L. Hanley, A. Amini, B.L. FoxDispersing single-walled carbon nanotubes in ionic liquids: a quantitative analysis RSC Adv., 3 (2013), pp. 20034-20049, 10.1039/C3RA42488J

CrossRefGoogle Scholar

I. Krossing, J.M. Slattery, C. Daguenet, P.J. Dyson, A. Oleinikova, H. WeingärtnerWhy are ionic liquids liquid? A simple explanation based on lattice and solvation energies, $\mathbf{J}$

Am. Chem. Soc., 128 (2006), pp. 13427-13434, 10.1021/ja0619612

P. Sun, D.W. ArmstrongIonic liquids in analytical chemistry

Anal. Chim. Acta, 661 (2010), pp. 1-16, 10.1016/j.aca.2009.12.007

S. Mallakpour, M. DinariIonic liquids as green solvents: progress and prospects

A. Mohammad, D. Inamuddin (Eds.), Green Solvents II: Properties and Applications of Ionic Liquids, Springer, Dordrecht, Netherlands (2012), pp. 1-32

R. Toniolo, R. Bortolomeazzi, R. Svigelj, N. Dossi, I.G. Casella, C. Bragato, S. DanieleUse of an electrochemical room temperature ionic liquid-based microprobe for measurements in gaseous atmospheres

Sens. Actuators B Chem., 240 (2017), pp. 239-247, 10.1016/j.snb.2016.08.139

M.J.A. Shiddiky, A.A.J. TorrieroApplication of ionic liquids in electrochemical sensing systems

Biosens. Bioelectron., 26 (2011), pp. 1775-1787, 10.1016/j.bios.2010.08.064 
F. Xiao, C. Ruan, L. Liu, R. Yan, F. Zhao, B. ZengSingle-walled carbon nanotube-ionic liquid paste electrode for the sensitive voltammetric determination of folic acid

Sens. Actuators B Chem., 134 (2008), pp. 895-901, 10.1016/j.snb.2008.06.037

S. Kang, W. Zhao, X. Li, Z. Wen, X. Niu, B. He, L. Li, W. SunElectrochemical behaviors of myoglobin on ionic liquid-graphene-cobalt oxide nanoflower composite modified electrode and its electrocatalytic activity

Int. J. Electrochem. Sci., 12 (2017), pp. 2184-2193, 10.20964/2017.03.64

Y. Ma, G. Zhan, M. Ma, X. Wang, C. LiDirect electron transfer of hemoglobin in a biocompatible electrochemical system based on zirconium dioxide nanotubes and ionic liquid

Bioelectrochemistry, 84 (2012), pp. 6-10, 10.1016/j.bioelechem.2011.09.003

Y. Song, H. Liu, L. Wan, Y. Wang, H. Hou, L. WangDirect electrochemistry of cytochromec based on poly (diallyldimethylammonium chloride)-graphene nanosheets/gold nanop s hybrid nanocomposites and its biosensing

Electroanalysis, 25 (2013), pp. 1400-1409, 10.1002/elan.201200524

C.G. Timóteo, A.S. Pereira, C.E. Martins, S.G. Naik, A.G. Duarte, J.J.G. Moura, P. Tavares, B.H. Huynh, I. MouraLow-spin heme $\boldsymbol{b}_{3}$ in the catalytic center of nitric oxide reductase from Pseudomonas nautica

Biochemistry, 50 (2011), pp. 4251-4262, 10.1021/bi101605p

M. Prudêncio, A.S. Pereira, P. Tavares, S. Besson, I. Cabrito, K. Brown, B. Samyn, B. Devreese, J. Van Beeumen, F. Rusnak, G. Fauque, J.J. Moura, M. Tegoni, C. Cambillau, I. MouraPurification, characterization, and preliminary crystallographic study of copper-containing nitrous oxide reductase from Pseudomonas nautica 617

Biochemistry, 39 (2000), pp. 3899-3907, 10.1021/bi9926328

U.K. LaemmliCleavage of structural proteins during the assembly of the head of bacteriophage T4

Nature, 227 (1970), pp. 680-685, 10.1038/227680a0

K.C. Wood, R.A. Alvarez, A.C. StraubChapter 18 - diffusional control of nitric oxide in the vessel wall A2 - Ignarro 
J. Louis, B.A. Freeman (Eds.), Nitric Oxide (Third Edition), Academic Press (2017), pp. 237-246

T.M. Oliveira, M. Fatima Barroso, S. Morais, M. Araujo, C. Freire, P. de LimaNeto, A.N. Correia, M.B. Oliveira, C. Delerue-MatosLaccase-Prussian blue film-graphene doped carbon paste modified electrode for carbamate pesticides quantification

Biosens. Bioelectron., 47 (2013), pp. 292-299, 10.1016/j.bios.2013.03.026

[39]

F. Faridbod, M.R. Ganjali, P. Norouzi, S. Riahi, H. RashediApplication of room temperature ionic liquids in electrochemical sensors and biosensors, Ionic liquids: applications and perspectives

$\operatorname{InTech}(2011), \underline{10.5772 / 14702}$

W. Wei, H.-H. Jin, G.-C. ZhaoA reagentless nitrite biosensor based on direct electron transfer of hemoglobin on a room temperature ionic liquid/carbon nanotube-modified electrode

Microchim Acta, 164 (2009), pp. 167-171, 10.1007/s00604-008-0053-y

Q. Zhang, W. Wei, G.C. ZhaoDirect electrochemistry of myoglobin on a room temperature ionic liquid modified electrode and its application to nitric oxide biosensing

Electroanalysis, 20 (2008), pp. 1002-1007, 10.1002/elan.200704139

X. Shangguan, J. Zheng, H. Zhang, H. TangDirect electrochemistry and electrocatalysis behaviors of glucose oxidase based on hyaluronic acidcarbon nanotubes-ionic liquid composite film

Chin. J. Chem., 28 (2010), pp. 1890-1896, 10.1002/cjoc.201090315

M.C. Rodriguez, A.-N. Kawde, J. WangAptamer biosensor for label-free impedance spectroscopy detection of proteins based on recognition-induced switching of the surface charge

ChemComm (2005), pp. 4267-4269, 10.1039/b506571b

Y. Zheng, Z. Liu, Y. Jing, J. Li, H. ZhanAn acetylcholinesterase biosensor based on ionic liquid functionalized graphene-gelatin-modified electrode for sensitive detection of pesticides

Sens. Actuators B Chem., 210 (2015), pp. 389-397, 10.1016/j.snb.2015.01.003 
S. Karimi, H. Ghourchian, P. Rahimi, H.-A. Rafiee-PourA nanocomposite based biosensor for cholesterol determination

Anal. Methods, 4 (2012), pp. 3225-3231

$[46]$

J.E. Nielsen, J.A. McCammonCalculating pKa values in enzyme active sites

Protein Sci., 12 (2003), pp. 1894-1901, 10.1039/C2AY25826A

[47]

P. Rahimi, H.-A. Rafiee-Pour, H. Ghourchian, P. Norouzi, M.R. GanjaliIonicliquid/NH2-MWCNTs as a highly sensitive nano-composite for catalase direct electrochemistry

Biosens. Bioelectron., 25 (2010), pp. 1301-1306, 10.1016/j.bios.2009.10.020

Q. Zhao, D. Zhan, H. Ma, M. Zhang, Y. Zhao, P. Jing, Z. Zhu, X. Wan, Y. Shao,

Q. ZhuangDirect proteins electrochemistry based on ionic liquid mediated carbon nanotube modified glassy carbon electrode

Front Biosci., 10 (2005), pp. 326-334, 10.2741/1530

Y. Yin, Y. Lü, P. Wu, C. CaiDirect electrochemistry of redox proteins and enzymes promoted by carbon nanotubes

Sensors, 5 (2005), pp. 220-234, 10.3390/s5040220

D. Grieshaber, R. MacKenzie, J. Vörös, E. ReimhultElectrochemical biosensors - Sensor principles and architectures

Sensors, 8 (2008), pp. 1400-1458, 10.3390/s80314000

X. Chen, J. Xuan, L. Jiang, J. ZhuPreparation of the glucose sensor based on three-dimensional ordered macroporous gold film and room temperature ionic liquid

Sci. China, Ser. B, Chem., 52 (2009), p. 1999, 10.1007/s11426-009-0249-y

R. Gao, J. Zheng, L. QiaoDirect electrochemistry of hemoglobin in layer-bylayer films assembled with DNA and room temperature ionic liquid Electroanalysis, 22 (2010), pp. 1084-1089, 10.1002/elan.200900373

S. Sajjadi, H. Ghourchian, P. RahimiDifferent behaviors of single and multi wall carbon nanotubes for studying electrochemistry and electrocatalysis of choline oxidase

Electrochim. Acta, 56 (2011), pp. 9542-9548, 10.1016/j.electacta.2011.04.039 
X. Lu, Q. Zhang, L. Zhang, J. LiDirect electron transfer of horseradish peroxidase and its biosensor based on chitosan and room temperature ionic liquid

Electrochem. Commun., 8 (2006), pp. 874-878, 10.1016/j.elecom.2006.03.026

A. Banaei, H. Ghourchian, P. Rahimi, A.A. Moosavi Movahedi, R. AmjadiDifferent electrochemical behavior of adult and fetal hemoglobin at ionic liquid-carbon nanotube nanocomposite

J. Iran. Chem. Soc., 12 (2015), pp. 687-694, 10.1007/s13738-014-0527-2

E. LavironAdsorption, autoinhibition and autocatalysis in polarography and in linear potential sweep voltammetry

J. Electroanal. Chem. Lausanne (Lausanne), 52 (1974), pp. 355-393, $\underline{10.1016 / \mathrm{S} 0022-0728(74) 80448-1}$

L. Lu, X. Huang, Y. QuEffect of the structure of imidazolium cations in [BF $]^{-}$type ionic liquids on direct electrochemistry and electrocatalysis of horseradish peroxidase in nafion films

Colloids Surf. B Biointerfaces, 87 (2011), pp. 61-66, $\underline{10.1016 / j . c o l s u r f b .2011 .04 .037 ~}$

Z. Zhu, X. Li, Y. Wang, Y. Zeng, W. Sun, X. HuangDirect electrochemistry and electrocatalysis of horseradish peroxidase with hyaluronic acid-ionic liquidcadmium sulfide nanorod composite material

Anal. Chim. Acta, 670 (2010), pp. 51-56, 10.1016/j.aca.2010.04.061

L. Yang, X.Q. Wu, R. Wang, Z.Q. Lu, W.J. Hou, H.X. LiIonic liquid modified GC electrode for the direct electrochemistry of chloroperoxidase Chin. Chem. Lett., 19 (2008), pp. 1483-1486, 10.1016/j.cclet.2008.09.040 nanoparticles for the direct electrochemistry of hemoglobin with carbon ionic liquid electrode

Biosens. Bioelectron., 26 (2011), pp. 2119-2124, 10.1016/j.bios.2010.09.017 
S. Dong, Z. Li, Z. Yu, Y. Zhou, H. TangDirect electrochemistry of hemoglobin immobilized in chitosan-room temperature ionic liquid film and application in its interaction with 3,4'-bis-(4-hydro-3-xycoumarin)-2,5-hexanediol

Colloids Surf. B Biointerfaces, 100 (2012), pp. 133-137, $\underline{10.1016 / \text { j.colsurfb.2012.05.009 }}$

Y. Zeng, W. Li, H. Zhang, X. Wu, W. Sun, Z. Zhu, Y. YuApplication of flowerlike $\mathrm{SnS}_{2}$ nanoparticles for direct electrochemistry of hemoglobin and its electrocatalysis

Anal. Methods, 6 (2014), pp. 404-409, 10.1039/C3AY41644E

Y. Ke, Y. Zeng, X. Pu, X. Wu, L. Li, Z. Zhu, Y. YuElectrochemistry and electrocatalysis of myoglobin on carbon coated $\mathrm{Fe}_{3} \mathrm{O}_{4}$ nanospindle modified carbon ionic liquid electrode

RSC Adv., 2 (2012), pp. 5676-5682, 10.1039/C2RA20362F

$[64]$

J.M. Berg, J. Tymoczko, L. StryerThe Michaelis-Menten model accounts for the kinetic properties of many enzymes

J.M. Berg, J.L. Tymoczko, L. Stryer (Eds.), Biochemistry (5 $5^{\text {th }}$ edition), W.H. Freeman, New York (2002)

A. Shrivastava, V. GuptaMethods for the determination of limit of detection and limit of quantitation of the analytical methods

Chron. Young Sci., 2 (2011), pp. 21-25, 10.4103/2229-5186.79345

$\mathrm{Y} . \mathrm{Xu}, \mathrm{C} . \mathrm{Hu}, \mathrm{S}$. HuElectrochemical behavior of biocatalytical composite based on heme-proteins, didodecyldimethylammonium bromide and roomtemperature ionic liquid

Anal. Chim. Acta, 663 (2010), pp. 19-26, 10.1016/j.aca.2010.01.015

F.O. Gomes, L.B. Maia, C. Cordas, C. Delerue-Matos, I. Moura, J.J.G. Moura, S. MoraisNitric oxide detection using electrochemical third-generation biosensors - based on heme proteins and porphyrins

Electroanalysis, 30 (2018), pp. 1-20, 10.1002/elan.201800421

S. Moncada, R.M. Palmer, E.A. HiggsNitric oxide: physiology, pathophysiology, and pharmacology

Pharmacol. Rev., 43 (1991), pp. 109-142 
F. Wang, X. Chen, Y. Xu, S. Hu, Z. GaoEnhanced electron transfer for hemoglobin entrapped in a cationic gemini surfactant films on electrode and the fabrication of nitric oxide biosensor

Biosens. Bioelectron., 23 (2007), pp. 176-182, 10.1016/j.bios.2007.03.027

A.A. Abdelwahab, W.C.A. Koh, H.-B. Noh, Y.-B. ShimA selective nitric oxide nanocomposite biosensor based on direct electron transfer of microperoxidase: removal of interferences by co-immobilized enzymes Biosens. Bioelectron., 26 (2010), pp. 1080-1086, 10.1016/j.bios.2010.08.070

[71]

W.C.A. Koh, M.A. Rahman, E.S. Choe, D.K. Lee, Y.-B. ShimA cytochrome c modified-conducting polymer microelectrode for monitoring in vivo changes in nitric oxide

Biosens. Bioelectron., 23 (2008), pp. 1374-1381, 10.1016/j.bios.2007.12.008

$[72]$

R.M. Santos, M.S. Rodrigues, J. Laranjinha, R.M. BarbosaBiomimetic sensor based on hemin/carbon nanotubes/chitosan modified microelectrode for nitric oxide measurement in the brain

Biosens. Bioelectron., 44 (2013), pp. 152-159, 10.1016/j.bios.2013.01.015

H.-Y. Gu, A.-M. Yu, S.-S. Yuan, H.-Y. ChenAmperometric nitric oxide biosensor based on the immobilization of hemoglobin on a nanometer-sized gold colloid modified au electrode

Anal. Lett., 35 (2002), pp. 647-661, 10.1081/AL-120003167

Z. Dai, Y. Xiao, X. Yu, Z. Mai, X. Zhao, X. ZouDirect electrochemistry of myoglobin based on ionic liquid-clay composite films

Biosens. Bioelectron., 24 (2009), pp. 1629-1634, 10.1016/j.bios.2008.08.032

J. Li, F. Zhao, G. Wang, Z. Gui, F. Xiao, B. ZengNovel composite of multiwalled carbon nanotubes and gold nanoparticles stabilized by chitosan and hydrophilic ionic liquid for direct electron transfer of glucose oxidase Electroanalysis, 21 (2009), pp. 150-156, 10.1002/elan.200804413

Q.-Q. Ren, J. Wu, W.-C. Zhang, C. Wang, X. Qin, G.-C. Liu, Z.-X. Li, Y. YuReal-time in vitro detection of cellular $\mathrm{H}_{2} \mathrm{O}_{2}$ under camptothecin stress using horseradish peroxidase, ionic liquid, and carbon nanotube-modified carbon fiber ultramicroelectrode 
Sens. Actuators B Chem., 245 (2017), pp. 615-621, 10.1016/j.snb.2017.02.001

$[77]$

X. Shangguan, J. Zheng, Q. ShengDirect electron transfer of horseradish peroxidase in gellan gum-hydrophilic ionic liquid gel film

Electroanalysis, 21 (2009), pp. 1469-1474, 10.1002/elan.200904550

[78]

C. Sheng, Y. Zhang, L. Wang, N. JiaImmobilization and bioelectrochemistry of hemoglobin based on carrageenan and room temperature ionic liquid composite film

Chin. J. Chem., 30 (2012), pp. 1565-1570, 10.1002/cjoc.201200113

L. Wang, X. Zhang, H. Xiong, S. WangA novel nitromethane biosensor based on biocompatible conductive redox graphenechitosan/hemoglobin/graphene/room temperature ionic liquid matrix

Biosens. Bioelectron., 26 (2010), pp. 991-995, 10.1016/j.bios.2010.08.027

M.G. Freire, C.M.S.S. Neves, P.J. Carvalho, R.L. Gardas, A.M. FernandesMutual solubilities of water and hydrophobic ionic liquids

J. Phys. Chem. B, 111 (45) (2007), pp. 13082-13089, 10.1021/jp076271e

Filipa Gomes received her degree in Chemistry from Universidade do Minho (Braga, Portugal) in 2009 and she obtained her Master's in 2011 in the field of Characterization Techniques and Chemical Analysis from the same university. Currently, she has a PhD fellowship in Sustainable Chemistry at REQUIMTE financed by Fundação para a Ciência e Tecnologia. Her main interests are bioelectrochemistry, in particular enzymatic biosensors; electrocatalysis and surface characterization.

Luisa B. Maia is a postdoctoral fellow in the group of José Moura, at the Universidade Nova de Lisboa (Portugal). She received her $\mathrm{PhD}$ in Pharmaceutical and Clinical Biochemistry from the Universidade de Lisboa (Portugal) for work on the new catalytic activities of mammalian molybdenum-containing enzymes relevant to human physiology and pathology. Her current research interests involve structure-activity relationships of metalloenzymes and reactive oxygen and nitrogen species biochemistry (formation, elimination and mechanisms of diseases), with particular emphasis on the metabolism of NO.

Cristina Delerue-Matos obtained her $\mathrm{PhD}$ in Chemical-Physics, specialty in electrochemistry, in 1990. At the moment, she is coordinator professor at the School of Engineering of the Polytechnic Institute of Porto (ISEP-IPP, Portugal) and also coordinates the REQUIMTE/ISEP research group (www.graq.isep.ipp.pt). Her research interests include the development of analytical methodologies for environmental, food, pharmaceutical, biochemical and industrial control. She is co-author of more than 300 publications in scientific journals. 
Isabel Moura received her Degree in Chemical Engineering from Technical University of Lisbon (Pt) in 1974; Masters in Physical Inorganic Chemistry in 1977 and PhD from New University of Lisbon (UNL) in 1981. She became Full Professor in 1997 at UNL, and visiting Professor in University of Georgia, Athens, USA. During the period she Head of the Chemistry Department of FCT/UNL (2000/2011) and Director of the Associated Laboratory REQUIMTE for Sustainable Chemistry. The main field of research is Bioinorganic Chemistry, Metals in Biology and Nitrogen Cycle. More than 400 publications, h-index 57. http://docentes.fct.unl.pt/isabelmoura

José G. Moura has a degree in Chemical Engineering, PhD in Chemistry and Full Professor at the Dept Chemistry, Faculdade de Ciências e Tecnologia, Universidade Nova de Lisboa. Research Specialist UMin (US) and Adjunct Professor at UGA (US). Past President of Dept Chemistry and President of Scientific Council at FCT-UNL, Delegate to COST and INTAS, member Scientific Panel FCG and FCT-MCTES, NSF (US) Specialized Panel, and several scientific editorial boards. In 2006, elected Member of Acad Ciências de Lisboa and in 2010, President of SBIC. Main research field: Bioinorganic Chemistry and Metals in Biology. More than 400 articles, h-index 58. http://docentes.fct.unl.pt/jigm

Simone Morais has a $\mathrm{PhD}$ (1998) in Chemical Engineering from the faculty of Engineering of the University of Porto. She is Associate Professor at the Department of Chemical Engineering at the School of Engineering of the Polytechnic of Porto (Portugal) and permanent researcher at REQUIMTE. Her main research interests are electrochemistry, (bio)sensors and environmental sciences. S. Morais co-authored about 110 papers in refereed and impact factor journals. 